\title{
AVALIAÇÃO DO COMPORTAMENTO DE BEZERROS DESMAMADOS EM DIFERENTES METODOLOGIAS
}

Danilo Pinheiro Prates ${ }^{1}$, Rogério Pinto ${ }^{2}$, Waleska De Melo Ferreira Dantas ${ }^{3}$, Sérgio Domingues ${ }^{4} ;{ }^{*}$ Idelvânia dos Anjos Nonato ${ }^{5}$

${ }^{1}$ Acadêmico em Medicina Veterinária - FAVIÇOSA/UNIVIÇOSA.

2 Professor do Curso de Medicina Veterinária - FAVICCOSA/UNIVICOSA.

${ }^{3}$ Professora do Curso de Medicina Veterinária - FAVIÇOSA/UNIVIÇOSA.

${ }^{4}$ Professor do Curso de Psicologia - FAVIÇOSA ${ }^{4}$

${ }^{5}$ Doutoranda do Programa de Pós-Graduação em Medicina Veterinária da Universidade Federal de Viçosa (UFV); vania.dosanjos@gmail.com*

Recebido em: 08/09/2015 - Aprovado em: 14/11/2015 - Publicado em: 01/12/2015 DOI: http://dx.doi.org/10.18677/Enciclopedia_Biosfera_2015_098

\begin{abstract}
RESUMO
Realizou-se uma pesquisa na cidade de Carlos Chagas - MG, em agosto de 2013, por meio da avaliação do comportamento de bezerros de gado de corte mestiços Nelore x Tabapuã e Nelore $x$ Indubrasil a dois métodos de desmame. No primeiro método (tratamento 1), os animais foram separados abruptamente de suas mães, e no segundo (tratamento 2), os animais foram desmamados e mantidos no mesmo Piquete com vacas madrinhas e seus bezerros ainda não desmamados, mantendose o mesmo grupo social. Foram avaliadas as reações dos animais perante os tratamentos propostos. Atos como balir, defecar, urinar, alto flagelar, tentativa de fuga, buscar proximidade, foram verificados e contabilizados quanto a sua intensidade e freqüência. Além das avaliações comportamentais, foram realizadas pesagens $1^{\circ}, 2^{\circ}$ e $7^{\circ}$ dias experimentais para avaliar do estado corporal dos animais ou possíveis alterações mediante estresse sofrido. Verificou-se que a desmama em ambos tratamentos provocou um intenso e rápido estresse nos bezerros em até 48:00 horas após separação mãe e filho, com aumento no hábito de caminhada, tentativa de fuga e no ato de balir. O desmame com uso de vacas madrinhas, promoveu estresse em menor intensidade para os bezerros, conferindo menor alteração no peso e no bem estar dos animais, apresentando-se como manejo mais adequado.
\end{abstract}

PALAVRAS-CHAVE: Bem estar animal, estresse, etologia, zootecnia.

\section{EVALUATION OF THE WEANED CALF IN DIFFERENT METHODOLOGIES}

\begin{abstract}
The research was conducted in the city of Carlos Chagas - MG, in August 2013, through the assessment of the behavior of calves for beef cattle crossbred Nelore $x$ Tabapuã and Nellore $x$ Indubrasil two methods of weaning. In the first method (treatment 1), the animals were separated abruptly from their mothers, and in the second (treatment 2), the animals were weaned and kept in the same Paddock with cows godparents and their calves still not weaned, maintaining the same social


group. Were the reactions of the animals before the proposed treatments. Acts as bleat, defecating, urinating, high scourged, attempt to escape, seek closeness, were recorded and accounted for in terms of its intensity and frequency. In addition to the behavioral evaluations, were weighed 1st, 2nd and 7th experimental days to assess the body condition of the animals or possible changes upon stress suffered. It was found that the weaning in both treatments caused an intense and rapid stress in calves up to 48:00 hours after separation of mother and son, with increase in habit of walking, attempt to escape and in the act of bleat. The weaning with use of cows godparents, promoted stress in lower intensity for the calves, giving lower change in weight and in the well-being of animals, presenting as more appropriate management.

KEYWORDS: Animal welfare, animal science, ethology, stresse.

\section{INTRODUÇÃO}

O Brasil possui o primeiro rebanho comercial do mundo, com cerca de 210 milhões de cabeça de gado, caracterizando se como o primeiro em exportações de carne bovina (IBGE, 2013). A pecuária representa $8 \%$ do produto interno bruto (PIB) (BRASIL, 2011). Em 2010, este mesmo autor citou que foram abatidas 22 milhões de cabeças de bovinos.

A criação de ruminantes domésticos, objetiva a produção de leite, carne e lã, com o menor custo de produção e melhor qualidade. Com isso, há necessidade de seleção dos animais pelo seu potencial produtivo e capacidade de adaptar-se ao ambiente (JOBIM \& JUNIOR, 2013).

Para aumentar esta produtividade, mudanças significativas foram realizadas no ambiente, pela intensificação dos sistemas de produção. Essas alterações resultaram em problemas para os animais, pois, a alta produtividade não significava manutenção do bem-estar animal (BROON \& FRASER, 2007).

Várias são as vertentes de pensamento em melhorias no desempenho produtivo dos animais. Ha uma necessidade de se realizar mais investimentos em melhoramento genético e no manejo animal, visando à melhoria do ganho produtivo (FILHO, 2009). Entretanto, os bovinos são animais gregários, vivem sempre em grupos. Quando um animal é isolado do rebanho, tornam se mais estressado. Além disse os animais ao serem submetidos a manejo intensivo ou em condições que são pouco apropriadas para suas necessidades sociais podem se tornar estressado, quando comparados àqueles que são submetidos ao sistema extensivo, onde há possibilidade de acesso mais fácil a outros animais, ou fatores ligados ao ambiente como instalações, sanidade oferta de alimento e água e ao transporte (COSTA et al., 2012; MIRANDA et al., 2013).

Um dos gargalos verificados na criação de gado de corte é a desmama, que é um período de muito estresse, tanto para a vaca quanto para o bezerro, que na maioria das propriedades e feita de forma abrupta (CERVIERI, 2007). Tradicionalmente a desmama é realizada aos 6 a 8 meses de vida dos bovinos, e neste período, ele já pode ser considerado ruminante, recomendando-se a utilização de dieta sólida como fonte de energia e nutrientes (EMBRAPA, 1996). No momento do desmame o comportamento do bezerro, bem como o seu desempenho devem ser avaliados, para verificar os possíveis impactos causados no processo de adaptação à nova alimentação (ENRÍQUEZ et al., 2011).

O conhecimento da biologia dos animais de produção e podem melhorar o bem-estar dos mesmos, o que irá provocar um aumento nos resultados econômicos, 
eficiência do sistema de produção ou ate mesmo obter produtos de melhor qualidade (HERNANDES et al., 2010).

O baixo controle no bem-estar animal diminui a produção de leite, ovos, no crescimento e na reprodução, aumentando a incidência de doenças e diminuindo a qualidade da carne e do ganho de peso dos animais. Dessa forma a expectativa de vida dos animais pode ser reduzida, ocorrendo lesões no corpo, imunossupressão, patologias comportamentais, dentre outras (HÖTZEL \& MACHADO, 2004).

Assim, quando no momento do desmame, são deflagrados vários eventos que podem ser agudos e prolongados para o bezerro, pois, fatores como a perda da mãe e do acesso ao úbere e leite, e as mudanças no ambiente social e físico podem ser estressores (ENRÍQUEZ et al., 2011). Este mesmo autor cita que esta ruptura de vínculo com a mãe, causa estresse pela perca na relação social existente. A relação prole e mãe podem ser explicadas em três fases: nos primeiros meses de vida, a mãe busca o contanto com o bezerro e mais tarde, este será responsável por se cuidar e ter um contato social, e por fim, a mãe passa a rejeitar tentativas de cuidados e contato pelo bezerro, até que este comportamento cesse. Além da obtenção de leite e cuidados, a mãe também proporciona conforto emocional para 0 bezerro, por isso há motivação em manter o laço social por ambas as partes.

O desmame também desencadeia uma mudança acentuada e progressiva no repertório geral de comportamento de bezerros, que começam a adotar um padrão mais típico de bovinos adultos (WEARY et al., 2008).

$\mathrm{Na}$ criação de gado de corte, o modelo de desmame utilizado é frequentemente o abrupto, justificado pela facilidade do manejo, não permitindo que este possa ocorrer de forma gradual e natural da espécie.

Assim, esta pesquisa objetivou comparar o método tradicional de desmama de bezerros, feito de forma abrupta com àquele utilizando vacas madrinhas, afim de observar e mesurar as manifestações de estresse ocorridas.

\section{MATERIAL E MÉTODOS}

A pesquisa foi realizada na cidade de Carlos Chagas - MG, em agosto de 2013, por meio da avaliação do comportamento de bezerros (machos ou fêmeas) de gado de corte mestiços Nelore x Tabapuã e Nelore $X$ Indubrasil em fase de desmame, após aprovação pelo Comitê de ética em pesquisa com o uso de animais da Faculdade de Ciências Biológicas e da Saúde FACISA/UNIVIÇOSA, sob número de protocolo 00101/2013-2.

A avaliação experimental se deu pelo acompanhamento e observação comportamental de bezerros submetidos a dois métodos de desmame, após a idade de $240 \pm 15$ dias. No primeiro método (tratamento 1), os animais foram separados abruptamente de suas mães, sendo estes colocados juntos em um piquet. No segundo método (tratamento 2), foi realizado o manejo de desmama dos bezerros, mantendo-os no mesmo piquet, junto com as fêmeas, chamadas madrinhas e seus bezerros ainda não desmamados, mantendo-se o mesmo grupo social .

Foi avaliado o comportamento de 15 bezerros em cada grupo experimental. Para avaliação foi utilizado um "checklist", para acompanhar as reações dos animais perante os manejos propostos de desmame. Atos como balir, defecar, urinar, auto flagelar, tentativa de fuga, buscar proximidade a outros animais foram verificados e contabilizados quanto a sua intensidade e freqüência absoluta e relativa durante sete dias. Durante as primeiras 48 horas, onde havia expectativa de maior estresse, as observações foram realizadas a cada duas horas. A parti do terceiro dia as 
observações foram mais espaçadas, ocorrendo duas observações pela manhã, inicio ao fim 8:00 h e 11:00 h e duas observações a tarde 13:00 e 17:00 horas, até o sétimo dia de avaliação. Além das avaliações comportamentais, foram feitas pesagens iniciais e durante 0 acompanhamento do experimento ao $1^{\circ}, 2^{\circ}$ e $7^{\circ}$ dia experimental, para avaliação do estado corporal dos animais ou possíveis alterações mediante estresse sofrido.

$\mathrm{Na}$ realização da pesagem inicial, foi tomado o cuidado de separar os animais com antecedência de duas horas de suas mães, para não ocorre alteração do peso corporal dos animais pela quantidade de leite ingerido antes da pesagem.

Uma vez coletados os dados, estes foram organizados por meio do software Excel $\AA$, e utilizados para posterior análise valendo-se do pacote estatístico Sistema Para Análises Estatí́sticas ${ }^{(18)}$, versão 9.1. A avaliação dos dados se deu por meio de freqüências absolutas e relativas das ocorrências comportamentais e cálculo da correlação das respostas estressoras pelo método de correlação de pearson, seguidas de sua interpretação biológica.

\section{RESULTADOS E DISCUSSÕES}

Quanto aos eventos comportamentais mais freqüentes, observados nos animais experimentais, que foram submetidos aos dois processos de desmame, podem ser citados 0 ato de caminhar, a tentativa de fuga, o constante ato de balir, aumento na freqüência de defecação e urina. Estas respostas estressoras foram observadas de formas intensas nos dois primeiros dias em ambos os tratamentos, ocorrendo diferenças de intensidades entre os métodos empregados, como pode ser verificado na figura 1 , para o ato de caminhar.

Quando estudado a freqüência com que os animais caminhavam, na busca por suas mães, após a separação no ato do desmame, verificou-se intensa atividade de todos os grupos estudados, principalmente no primeiro dia. Entretanto, no tratamento com o uso de vacas madrinhas, a intensidade do estresse verificado foi menor, sendo constatado por uma flutuação do número de animais que realizavam tal prática (primeiro dia de observação). Já na manhã seguinte à retirada das mães, os animais em ambos os tratamentos já se apresentavam mais parados, cessando a resposta intensa de caminhada, anômala àquela realizada para buscar alimento, água e reorientar-se para um melhor conforto térmico buscando sombra, etc. $\mathrm{O}$ ato de caminhar cessou rapidamente em ambos os tratamentos, sendo mantido por mais tempo no tratamento utilizando desmame abrupto, mas não excedendo no segundo dia, onde a partir daí o ato de caminhar pode ser considerado normal. $\mathrm{O}$ desmame é o período mais estressante para o bezerro em toda sua vida, e por isso, ao ser separado de sua mãe há uma reação intensa (GALLO, 2013). 


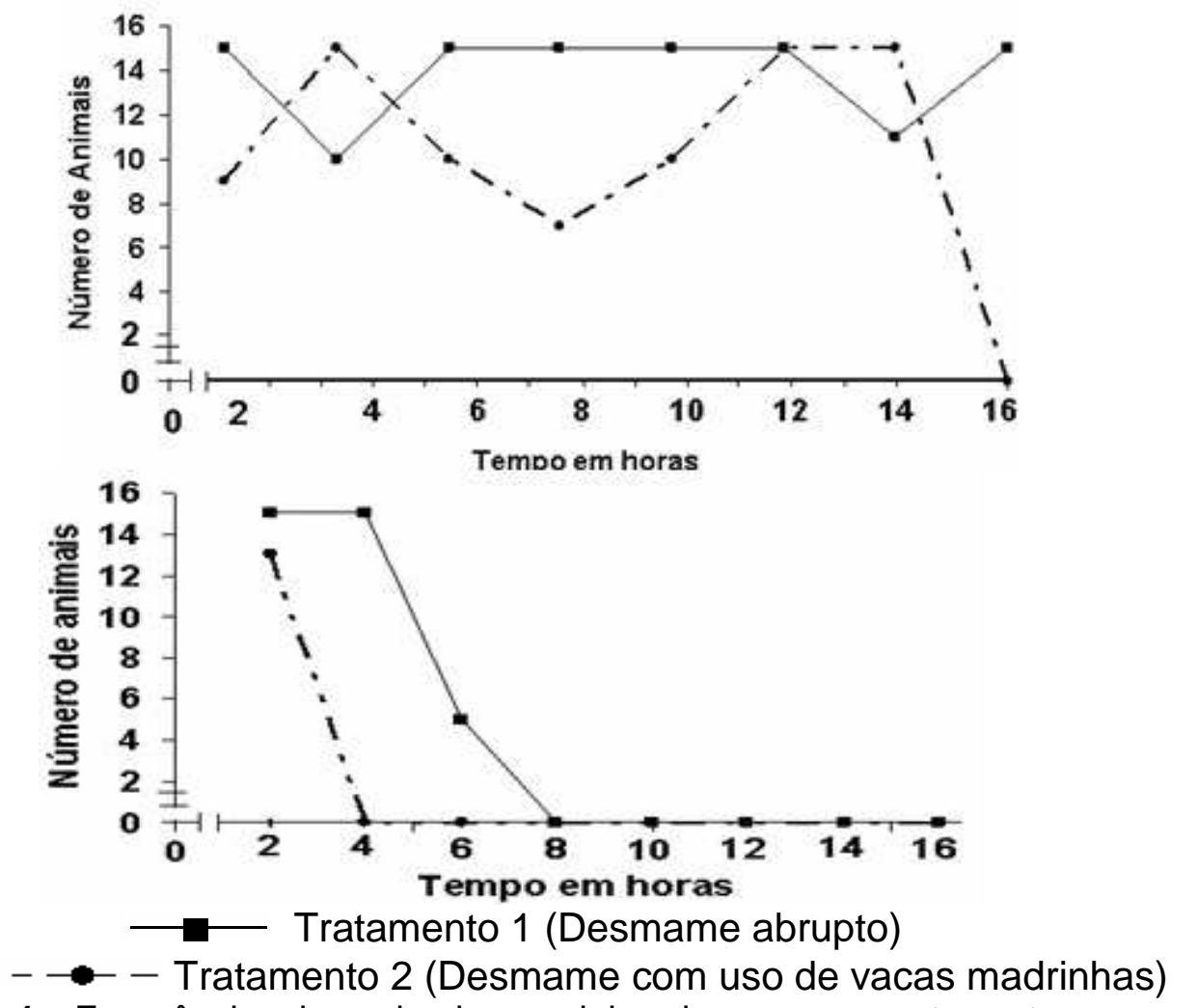

FIGURA 1: Frequência de animais caminhando por resposta estressora aos tratamentos de desmame de forma abrupta e com vacas madrinhas no primeiro $(A)$ e segundo (B) dias de avaliação.

As respostas biológicas, como comportamental, de sistema nervoso central, do sistema neuroendócrino e sistema imune são acionadas assim que o sistema nervoso central dos animais identifica um desafio nas pesquisas (MOBERG, 2000).Uma vez que a alteração de seu comportamento é uma das primeiras respostas do animal a uma situação de estresse, pois este tenta evitar o agente estressor ou minimizar o seu efeito (RUSHEN, 2000).

Os animais também apresentaram um comportamento de fuga, Figura 2, no qual, os bezerros tentavam sair constantemente do Piquete. Verificou-se que na desmama abrupta, os animais apresentaram uma maior frequência para tentativa de fuga, em relação ao outro tipo de manejo, comprovando o maior estresse provocado. Havia uma tentativa em forçar os cercados para fugir. Entretanto, este evento não deve ser confundido com aquele de se autoflagelar, pois em nenhum momento ocorreu tal comportamento em nenhum dos tratamentos.

A manutenção do grupo social, no método com vacas madrinhas, promoveu melhor ambientação para os bezerros desmamados, pois estes já conheciam o local e os outros animais ali existentes (vacas e outros bezerros). De uma forma geral o ideal, é manter os bezerros na mesma área em que estavam acostumados, pois assim, já estariam familiarizados com o ambiente (pastos, bebedouros, comedouros, etc) (CERVIERI, 2007). 

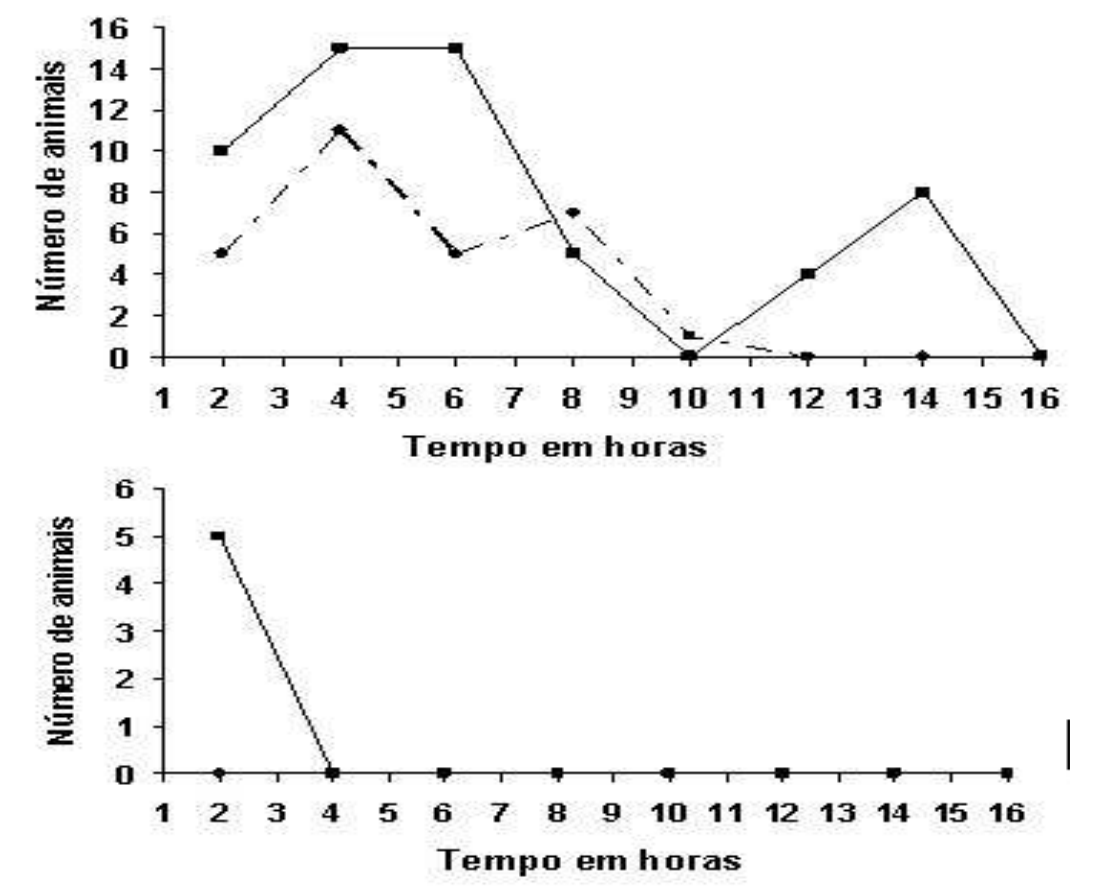

\section{- Tratamento 2 (Desmame com uso de vacas madrinhas)}

FIGURA 2: Frequência de animais em comportamento de fuga por resposta estressora aos tratamentos de desmame de forma abrupta e com vacas madrinhas no primeiro (A) e segundo (B) dias de avaliação.

Quanto ao comportamento de balir, verificou-se que este ato, juntamente com o de movimentar-se e tentativa de fuga foram os mais frequentes e com uma constancia maior, Figura 3. Por não estarem em piquetes próximos, os animais tentavam constantemente realizar algum contato com as mães. O método de desmame abrupto foi o que gerou maior reação nos bezerros, podendo ser observado um número de até 15 animais inicialmente balindo, decaindo este comportamento no decorrer do período. 

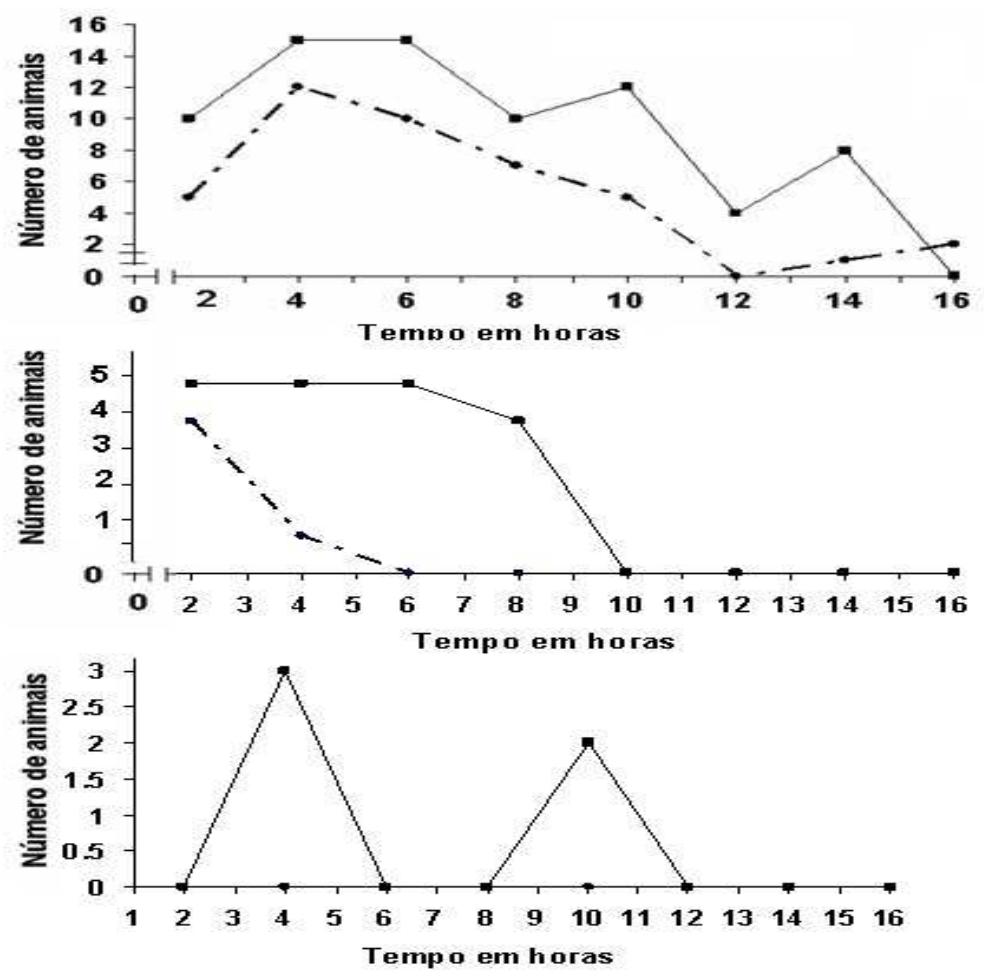

Tratamento 1 (Desmame abrupto)

- - - Tratamento 2 (Desmame com uso de vacas madrinhas)

FIGURA 3: Frequência de animais balindo em resposta estressora aos tratamentos de desmame de forma abrupta e com vacas madrinhas no primeiro (A), segundo (B) e sétimo (C) dias de avaliação.

Para o método de desmame, com a presença de vacas madrinhas, em nenhum momento o número de animais balindo excedeu a 5 , ocorrendo também a diminuição da intensidade no decorrer do tempo. Somente para o método abrupto, aos sete dias ainda havia animais balindo em busca de um contato com a mãe.

A separação prematura da mãe leva a vocalizações prolongadas, inquietação, atividade intensa e algumas vezes geram comportamentos anômalos que se manifestam até na vida adulta (HÖTZEL \& MACHADO, 2004). Quando um animal vivência uma situação de medo ou dor, sua fisiologia e comportamento passam por modificações envolvendo o sistema nervoso, endócrino, postura, movimentos corporais e outros (GALLO, 2013).

O bem-estar animal é reduzido quando estes têm sentimentos negativos, ou seja, sofrem e nestes sentimentos pode ser incluída a frustração, o medo, dor, solidão, aborrecimento e talvez até sentimentos que não ocorrem em seres humanos (LIMA \& FILHO, 2013).

Quanto ao comportamento de urinar e defecar, figura 4, verificou-se que no primeiro dia houve o aumento deste comportamento para até 5 animais em cada tipo de manejo avaliado. No decorrer dos dias, verificou-se que o número de evacuações $\mathrm{e} O$ ato de urinar dos animais haviam diminuído a uma quantidade inferior à normal. Em caso de estresse há uma mudança na fisiologia e também no metabolismo envolvendo o desenvolvimento do rúmen e a transição de pré-ruminal para ruminante funcional (HÖTZEL \& MACHADO, 2004).

Em momento o sistema gastrointestinal e as glândulas exócrinas são suprimidos, ocorrendo diminuição do peristaltismo e secreções, 
refletindo na diminuição da excreção de urina. Pode-se inferir também que, devido à alimentação estar diminuída em ambos os tratamentos em função do estresse, a frequência em urinar e defecar também foi diminuída (PETERS et al., 2007; HONORATO et al., 2012)
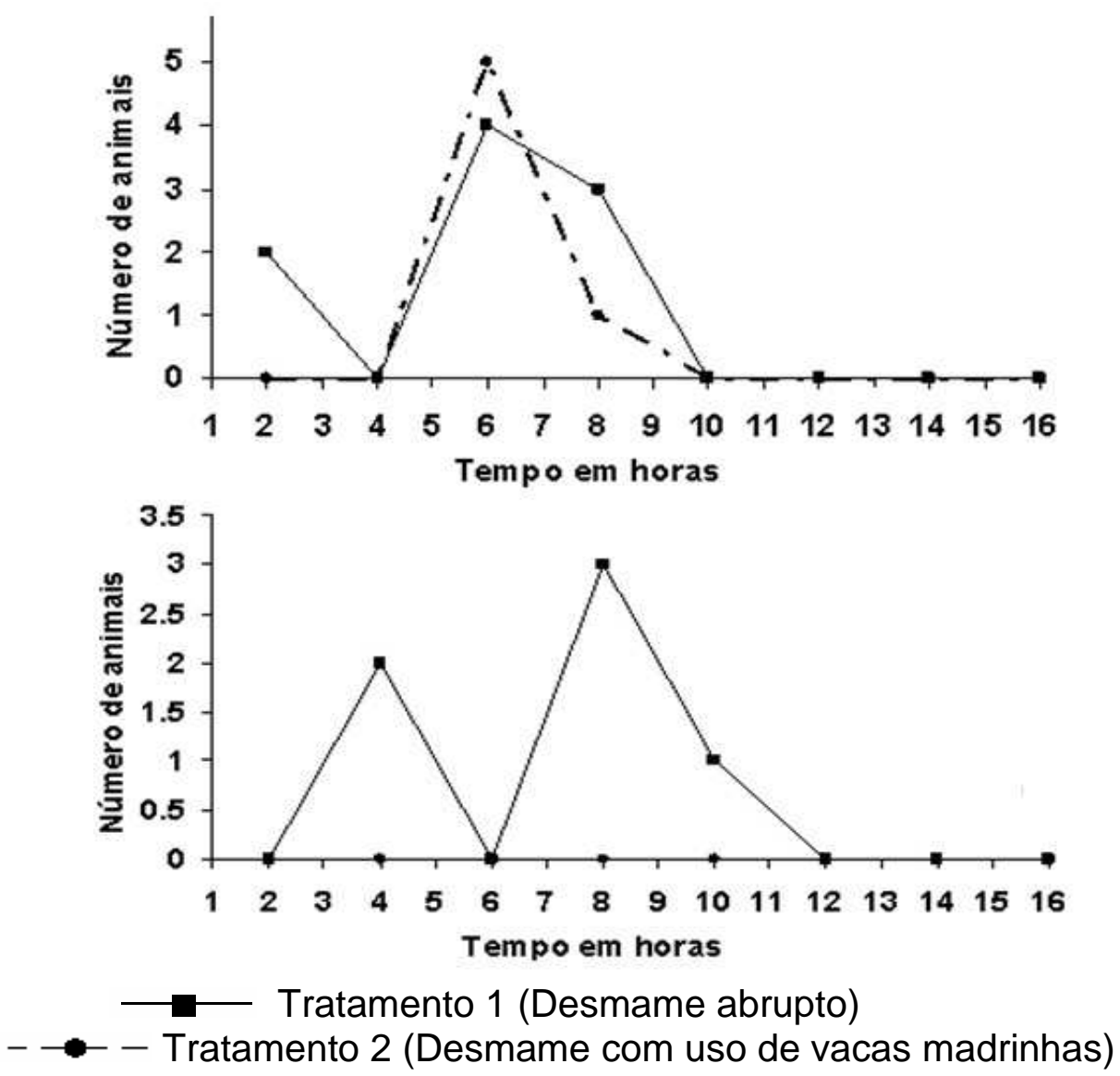

FIGURA 4: Frequência de animais defecando e urinando em resposta estressora aos tratamentos de desmame de forma abrupta e com vacas madrinhas no segundo $(A)$ e sétimo (C) dias de avaliação.

$\mathrm{Na}$ figura 5, verifica-se que houve perda de peso para os animais submetidos a ambos os tratamentos. Vários foram os eventos de estresse verificados que justificam esta diminuição de peso durante os dois primeiros dias de desmame, mas entre eles pode ser citada a retirada completa da dieta líquida, passando a sólida, o que irá denotar toda uma modificação no padrão da fisiologia digestiva deste animal, e também a constante movimentação dos animais.

Verificou-se para os dois tratamentos perda de peso dos animais, sendo respectivamente de $3,0 \mathrm{~kg}$ para os animais submetidos ao desmame com uso de vacas madrinhas e $6,0 \mathrm{~kg}$ para os animais submetidos a desmama abrupta, nos dois primeiros dias experimentais. 


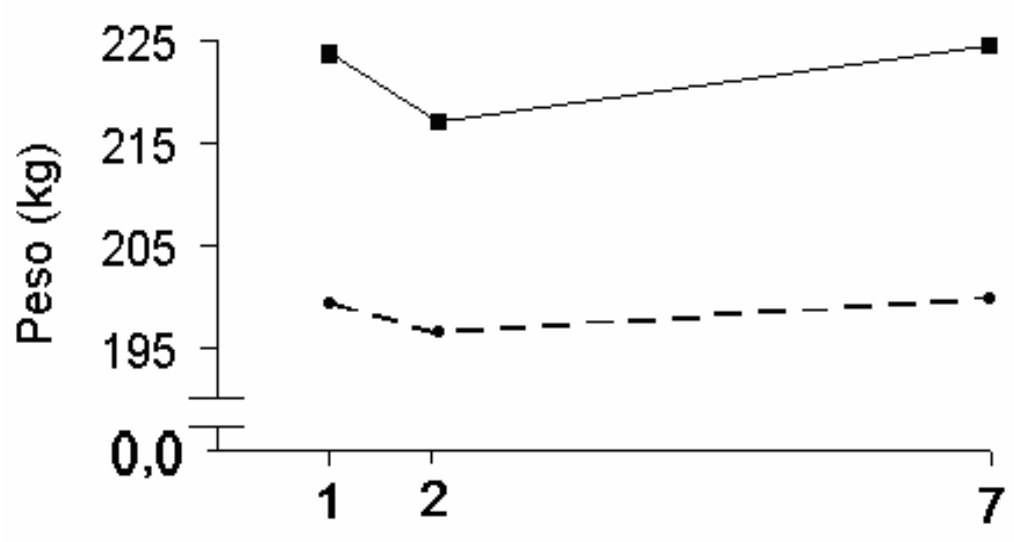

Período (Dias)

\section{$\longrightarrow$ Tratamento 1 (Desmame abrupto) \\ - - - Tratamento 2 (Desmame com uso de vacas madrinhas)}

FIGURA 5: Valores observados para pesagens dos animais submetidos ao desmame de forma abrupta e com vacas madrinhas no período estudado.

Estudos avaliados em bovinos observou-se que os animais perdem $0,48 \mathrm{Kcal} /$ $\mathrm{Kg}$ de peso corporal por metro percorrido, quando em movimentação intensa (SOUSA, 2005). Em situações onde o manejo propicie injúrias e medo nos animais, este pode levar à diminuição da eficiência alimentar, redução do valor da carcaça, aumentos da mortalidade animal, entre outras (BROON \& FRASER, 2007). as práticas de manejo, e o projeto inadequado das instalações utilizadas na criação animal, podem levar a prejuízos para o bem-estar, pois, um manejo alimentar inadequado diminui a motivação alimentar dos animais, podendo gerar déficits, apesar de terem seus suprimentos nutricionais atendidos (HÖTZEL \& MACHADO, 2004).

A rápida resposta de "alarme", conhecida como Síndrome de Emergência e a resposta do organismo durante um período mais longo ao estresse, conhecida como a Síndrome Geral da Adaptação, atuam sobre o metabolismo orgânico, aumentando - catabolismo protéico, a gliconeogênese no fígado, inibindo a absorção e a oxidação da glicose, além de estimular o catabolismo de triglicerídeos no tecido adiposo (SOUSA, 2005). A importância disso está no fato de que os estressores crônicos mobilizam energia constantemente, desviando-a da produção (LIMA \& FILHO, 2013).

$\mathrm{Na}$ tabela 1, pode ser observada a correlação entre as respostas comportamentais, em cada tipo de desmame estudado, por meio dos índices verificados para correlação de Pearson. Para efeitos correlacionados de caminhar e fuga, verificou-se um índice para correlação de Pearson de 0,5306 para o método abrupto e 0,5747 para o método de vacas madrinhas. Para os dois métodos percebeu-se que havia um comportamento similar, pois a orientação dos animais pela caminhada estava ligada à tentativa de fuga, ocorrendo um efeito sinérgico dos eventos. Ou seja, o ato de caminhar estava ligado a uma reorientação do animal na busca de possíveis áreas de fuga no piquete, que possivelmente seria em busca de sua mãe. 
TABELA 1 - Correlações entre as respostas comportamentais verificadas para os bezerros segundo os métodos de desmame empregados

\begin{tabular}{llccc}
\hline $\begin{array}{l}\text { Tipos de } \\
\text { desmame }\end{array}$ & $\begin{array}{l}\text { Variáveis } \\
\text { correlacionadas }\end{array}$ & Observações & Correlações & Significância \\
\hline \multirow{3}{*}{ Abrupto } & Caminhar x Fuga & 24 & 0.531 & 0.0038 \\
& Caminhar x Balir & 24 & 0.654 & 0.0003 \\
& Fuga x Balir & 24 & 0.906 & 0.0000 \\
& & & & \\
Uso de vacas & Caminhar x Fuga & 24 & 0.575 & 0.0017 \\
madrinhas & Caminhar x Balir & 24 & 0.711 & 0.0000 \\
& Fuga x Balir & 24 & 0.824 & 0.0000 \\
\hline
\end{tabular}

Animais, submetidos a uma situação de dor ou medo, tem o seu comportamento e fisiologia modificados por mudanças, envolvendo vários aspectos do sistema endócrino, postura, nervoso, movimentos corporais e outros. Para identificar o bem estar animal, deve-se avaliar o comportamento e o desempenho, pois variações negativas nestes podem ser interpretadas como sinalização de estado negativo (GALLO, 2013).

Qualquer evento no ambiente que cause modificação no comportamento do animal é considerado estressor (BAETA \& SOUZA, 2010). Os comportamentos de caminhar $\mathrm{x}$ balir apresentaram correlações para ambos os métodos de desmame, sendo respectivamente de 0,654 e 0,711, para o método abrupto e uso de vacas madrinhas.

Percebeu-se por meio de análise da correlação de Pearson, que os eventos fuga e balir para ambos os tratamentos foram os que apresentaram maior efeito, para ambos os tipos desmame. Para o método abrupto verificou-se uma correlação de 0,906 e para o método com vacas madrinhas 0,824 . Ao analisar a intensa vocalização dos animais, correlacionado com uma tentativa de fuga, nos permite inferir que este comportamento seria o de buscar estabelecer um contato com sua mãe. Por estarem em Piquetes separados e sem estabelecer nem contato visual entre eles, percebeu-se grande estresse a estes animais, tanto no manejo abrupto quanto aquele usando vacas madrinhas. Entretanto no segundo tratamento (uso de vacas madrinhas), ocorreu uma interrupção mais rápida esta procura pela mãe. Pode-se inferir que esta interrupção foi devido a um ambiente mais favorável, pela presença de outros animais, vacas e bezerros, configurando maior sensação de segurança para os bezerros desmamados.

\section{CONCLUSÕES}

Verificou-se que a desmama em ambos os tratamentos provoca um intenso e rápido estresse nos bezerros em até 48:00 horas após separação mãe e filho, com aumento no hábito de caminhada, tentativa de fuga e no ato de balir. Houve perda de peso dos animais nos tratamentos, durante os dois primeiros dias experimentais.

O desmame com uso de vacas madrinhas, promoveu estresse em menor intensidade para os bezerros, conferindo menor alteração no bem estar dos animais, apresentando-se como manejo mais adequado. 


\section{REFERENCIAS}

BAÊTA, F. C.; SOUZA, C. F. Ambiência em Edificações Rurais: Conforto Animal. $2^{\mathrm{a}}$ ed. UFV: Universidade Federal de Viçosa, Viçosa - MG, 2010. 269p.

BRASIL. Ministério da Agricultura, Pecuária e Abastecimento. Projeções do Agronegócio: Brasil 2010/2011 a 2020/2021, Assessoria de Gestão Estratégica. Brasília, 2011, 56p.

BROON, D. M.; FRASER, A. F. Domestic animal behavior and welfare. 2007. Disponível em: <http://bookshop.cabi.org/Uploads/Books/PDF/9781845932879/9781845932879.pdf $>$ Acessado em 05 de outubro de 2013.

CERVIERI, R. Alternativas para desmama de bezerros de corte. 2007. Disponível

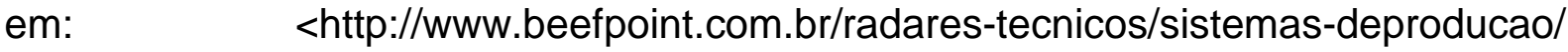
alternativas-para-desmama-de-bezerros-de-corte-34426/> Acesso em 10 de outubro de 2013.

COSTA, M. J. R. P.; HUERTAS, S. M.; GALLO, C.; COSTA, O. Strategies to promote farm animal welfare in Latin America and their effects on carcass and meat quality traits. Meat Science, v. 92, Issue 3, p. 221-226, 2012.

ENRÍQUEZ, D.; HÖTZEL, M. J.; UNGERFELD, R. Minimising the stress of weaning of beef calves: a review. Acta Veterinaria Scandinavica, v.53, n.28, p.1-8, 2011.

EMBRAPA-CNPGC. Desmama em bovinos de corte. Gado de corte divulga. Campo Grande-MS, 1996.

FILHO, K. E. Evolução do melhoramento genético de bovinos de corte no Brasil. Revista Ceres, Viçosa, v.56, n.5, p.620-626, 2009.

GALLO, M. P. C. 90f. 2013. Desempenho e alterações metabólicas e comportamentais de bezerros leiteiros em função do estresse ao desaleitamento. Dissertação de Mestrado (Ciência animal e Pastagens). Escola Superior de Agricultura "Luis de Queiroz" - ESALQ/USP.

HERNANDES, J. F. M.; RUBIN, L. S.; DILL, M. D.; OLIVEIRA, S. M.; SILVA, T. N. Bem-estar animal na cadeia produtiva bovina: da propriedade rural ao abate. Sociedade Brasileira de Economia, Administração e Sociologia Rural. In: 48o SOBER. Sociedade Brasileira de Economia, Administração e Sociologia Rural. Campo Grande, 2010.

HÖTZEL, M. J.; MACHADO, F. L. C. P. Bem-estar Animal na Agricultura do Século XXI. Revista de Etologia: Bem-estar animal e agricultura., n.6, nף, p.3-15. 2004.

HONORATO, L. A.; HÖTZEL, J. M.; GOMES, C. C. M.; SILVEIRA, I. D. B.; FILHO, L. C. P. M. Particularidades relevantes da interação humano-animal para o bem-estar e produtividade de vacas leiteiras. Ciência Rural, Santa Maria, v.42, n.2, p.332-339, 
2012.

Instituto Brasileiro de Geografia e Estatística - IBGE. 2013. Disponível em: http://saladeimprensa.ibge.gov.br/noticias. Acesso em: 20/11 /2013.

JOBIM, C. C.; JUNIOR, V. H. B. Avanços no uso de silagem de capim para bovinos de corte. Simpósio Brasileiro de Produção de Ruminantes. In: Anais do II Simpósio Brasileiro de Produção de Ruminantes, P.156-164, 2013.

MIRANDA, D. L.; CARVALHO, J. M.; TOMÉ, K. M. Bem-estar animal na produção de carne bovina brasileira. Informações Econômicas, v. 43, n. 2, p.46-46, 2013.

LIMA, L. R.; FILHO, J. A. D. Impacto do manejo pré-abate no bem-estar de caprinos e ovinos Impact of pre-slaughter management on the welfare of goats and sheep. Journal of Animal Behaviour and Biometeorology, v.1, n.2, p.5260, 2013.

MOBERG, G. P. Biological Response to Stress: implications on animal Welfare. In: In: MOBERG G.P.; MECH, J.A. The biology of animal stress, basic principles, implicatins for animal welfare. Edinburg, cab 2000, Cap. 1., p.1-21.

PETERS, M. D. P.; BARBOSA SILVERIRA, I. D.; RODRIGUES, C. M. Interação humano e bovino de Leite: revisão de literatura. Arquivo de Zootecnia., v.56, p.923. 2007.

RUSHEN, J. Some issues in the interpretation of bebhavioural responses to stress. In: MOBERG G. P.; MECH, J. A. The biology of animal stress, basic principles, implicatins for animal welfare. Edinburg, cab 2000. Chap.2.p.23.

SAEG - Sistema para Análises Estatísticas, Versão 9.1: Fundação Arthur Bernardes - UFV - Viçosa, 2007.

SOUSA, P. Exigências Atuais De Bem-Estar Animal E Sua Relação Com A Qualidade Da Carne. Embrapa Suínos e Aves. 2005. Disponível em <https://www.google.com.br/\#q=ZULKIFLI\%2C+l.\%3B+SIEGEL\%2C+P.B.+ls+there+ a+positive+side+of+stress\%3F+Poult.+Sci.+J.+V.+51\%2C+p.+6376\%2C+ 1995>. Acessado em 10 de outubro de 2013.

WEARY, D. M.; JASPER, J.; HÖTZEL, M. J. Understanding weaning distress. Applied Animal Behavior Science., v.110, Issues 1-2, p.24-41, 2008. 